International Journal of Distributed and Parallel Systems (IJDPS) Vol.3, No.5, September 2012

\title{
ENHANCING HIGHWAY TRAFFIC SAFETY THROUGH INTELLIGENT CAR
}

\author{
Dr. Sudha Singh ${ }^{1}$, S C Dutta ${ }^{2}$, Dr D K Singh ${ }^{3}$ and S K Singh ${ }^{4}$ \\ ${ }^{1}$ Associate Professor, PG Department of Computer Science and Engineering, Bengal \\ college of Engg. and Technology Bidhannagar, Durgapur-713212. West Bengal. \\ sudha_2k6@yahoo.com \\ ${ }^{2}$ Lecturer, Department of Computer Science and Engineering, \\ BIT Sindri, Dhanbad-828123. \\ dutta_subhash@yahoo.com \\ ${ }^{3}$ Professor, Department of Electrocics and communication Engineering, National \\ Institute of Technology, Patna-800005. \\ dksingh_biteyahoo.com \\ ${ }^{4}$ Senior Consultant, Telcomm department,Capjemini,Banglore-560037. \\ sujeet.a.singh@capjemini.com
}

\begin{abstract}
:
The transportation domain has already moved towards intravehicle intelligent spaces. In this paper, we will use various wireless technologies for traffic safety. This safety will be provided by developing a model for intelligent transportation system applications using emerging wireless communication technology in emergency situations. The performance analysis of the proposed model will be carried out. The experimental results will be also demonstrated. In this paper, we also propose some improvements in infrastructure of highway for better traffic control and safety.
\end{abstract}

Keywords: Intelligent car, Global Positioning System (GPS), GPRS, RFID, Face recognition, finger print recognition

\section{INTRODUCTION}

An intelligent car is an automobile with smart features, integrated circuits, artificial intelligence functionality and which is fully supported by wireless communication technologies. We can compare it with smart car [18]. Basic concepts of GPS is well known [6,13]. General packet radio service (GPRS) is a packet oriented mobile data service on the $2 \mathrm{G}$ and $3 \mathrm{G}$ cellular communication systems in global system for mobile communications (GSM). Radio-frequency identification (RFID) is a technology that uses communication via radio waves to exchange data between a reader and an electronic tag attached to an object, for the purpose of identification and tracking. A face recognition system is a computer application for automatically identifying or verifying a person from digital image [3]. Fingerprint recognition refers to the automated method of verifying a match between two human fingerprints. 
International Journal of Distributed and Parallel Systems (IJDPS) Vol.3, No.5, September 2012

Previous studies in this area are summarized in section II-Literature review. In section III, working model of an intelligent car is presented, briefly summarizing the working of an intelligent car. Section IV will have the proposed view of the infrastructure of the highway of this car. Section $\mathrm{V}$ will have the performance analysis of the proposed model and experimental results. Finally conclusions are drawn in section VI with further research directions are identified.

\section{LITERATURE REVIEW}

There have been significant research work in this and related areas in past decade. Most of these works have led researchers to design or simulate the system as a next step. We have a automotive safety function called emergency lane assist[7], a strategy on vehicular velocity controlling to meet both the demands of collision avoidance and best following performance which aims to guarantee traffic safety and improve the transportation efficiency [2]. Hillenbrand et al [11] investigate the performance of a practical, uncooperative collision migration system, capable of handling cross traffic on variety of intersection like situations. To improve safety in an automobile transportation, Zocci et al[19] gives the idea which deals with the methodology of using biorobotics principles for creating a new intelligent system. Brannstrom et al[5] presents a situation assessment algorithm that estimates driver distraction by continuously assessing the steering action by driver. Different types and levels of collision avoidance systems have been proposed $[5,16,1]$. We have studied the description about the application of GPS card meant for navigational system by infrared control of the cars in foggy condition to avoid accident along with micro central system [6]. There is also a case study [4] which addresses the characteristics of the road accident patterns including drowsy/sleepy drivers. This study proposes architecture for integrating intelligent control systems into vehicles, with special consideration to include the human driver in the control loop. We have also studied driver assistance system [14] and sound source guidance system [17]. The various scientist and researchers have worked on driving simulations, forward collision detection, intelligent traffic light, characterization of the expert drivers, movement detection techniques, wireless tire pressure monitoring system, stolen vehicle tracking system, automatic route guidance system, vehicle to vehicle communication, vehicle to roadside communication, electronic toll collection system, weather alert, danger alert etc. Researchers have also developed traffic flow forecasting algorithm and agent based control for network traffic system. Recently, a vehicle communication system used Bluetooth enabled cameras to collect and disseminate road congestion and accident information. The transportation domain has already moved towards intravehicle intelligent spaces. Now a day's people are getting more and more conscious and secure since wireless communication technologies are being combined with the ability to monitor a vehicle performance [12].

Here, we will use various wireless technologies for traffic safety. In this paper we are giving a working model of an intelligent car which is using given infrastructure, wireless communication technologies, existing technologies for road and car safety. The car which will run with this model will be called secured intelligent electronic car. 
International Journal of Distributed and Parallel Systems (IJDPS) Vol.3, No.5, September 2012

\section{THE PROPOSED MODEL WITH WORKING OF AN INTELLIGENT ELECTRONIC CAR}

The internal system of the electronic car is made up of intelligent data collection system (car electronic data (like engine oil, brake oil, fuel level, tire pressure etc.), GPRS etc), car information (like registration number, engine number etc.) and multiple recognition (like finger prints and face recognition to find out whether driver is authentic). The collected car information is verified through data server. If it is found ok then car will be ready to move otherwise it will display a proper message. This message will be displayed on the information screen available in front of the driver seat. This car will have sensors on front side and back side and there will be an antenna on the top of the car. In this way car will get external information in wireless manner. This electronic car will automatically store its internal and external information in every 5 seconds to get updated. In case of emergency, it may activate systems like automatic cruise control, speed controller, air bag, emergency call, wireless information to nearby stations etc according to the need. Since different factors contribute to vehicle crashes, such as vehicle mechanical problems and bad weather, driver's behavior is considered to be the leading cause of more than $90 \%$ of all accidents. The proposed model will not only give more time to driver to react in emergency situation but it will also support him. This is possible because proposed electronic system will recognize emergency condition much before, if it will occur. In case of emergency, information will be stored in the data server (in every second) so that later we can analyze it. 
International Journal of Distributed and Parallel Systems (IJDPS) Vol.3, No.5, September 2012



Fig. 1: Working of an Intelligent Car 
International Journal of Distributed and Parallel Systems (IJDPS) Vol.3, No.5, September 2012

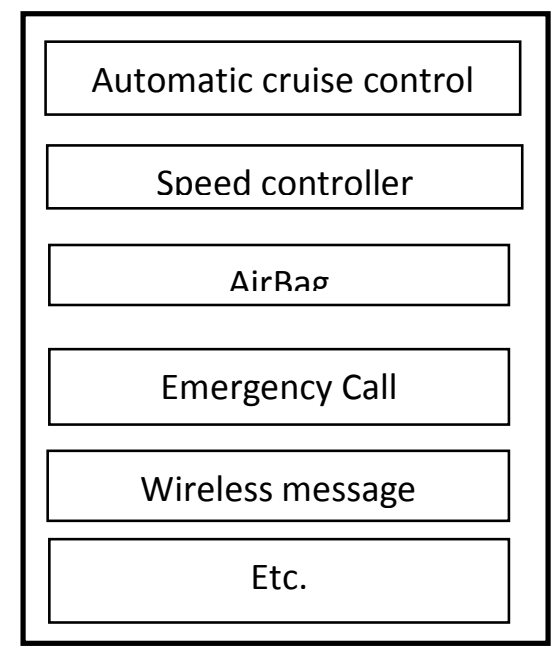

Fig. 2: Parts of Emergency system

In this way, electronic car will able to prevent

1. Theft,

2. Accidents due to poor mechanical status and maintenance of the car,

3. Accidents due to the poor weather,

4. Accidents due to high speed road,

5. Accidents due to drowsiness and sleepiness or any such type of driver's condition,

6. Driver's mistake,

7. Loneliness of the driver,

8. Problems occur during late night hours.

\section{PROPOSED VIEW OF HIGHWAY FOR ELECTRONIC CAR}

A view of highway system for electronic car is given in figure 3. In addition to existing infrastructure, it has the following:

1. Traffic information board ( it will be led display board) on both side of the road, so that only incoming and outgoing vehicles can see information without any confusion.

2. Traffic lights in between the crossings, it will be also on the both side of the road for incoming and outgoing traffic.. Colors will be green, red and yellow. We all ready know about Green and red, Yellow means go cautiously and slowly till you get green light ahead. Blinking yellow means traffic jam ahead, blinking red means major accident ahead and total traffic jam etc.

3. For getting full wireless signal on the road, infrastructure requires devoted satellite service, traffic service station, tower etc. 


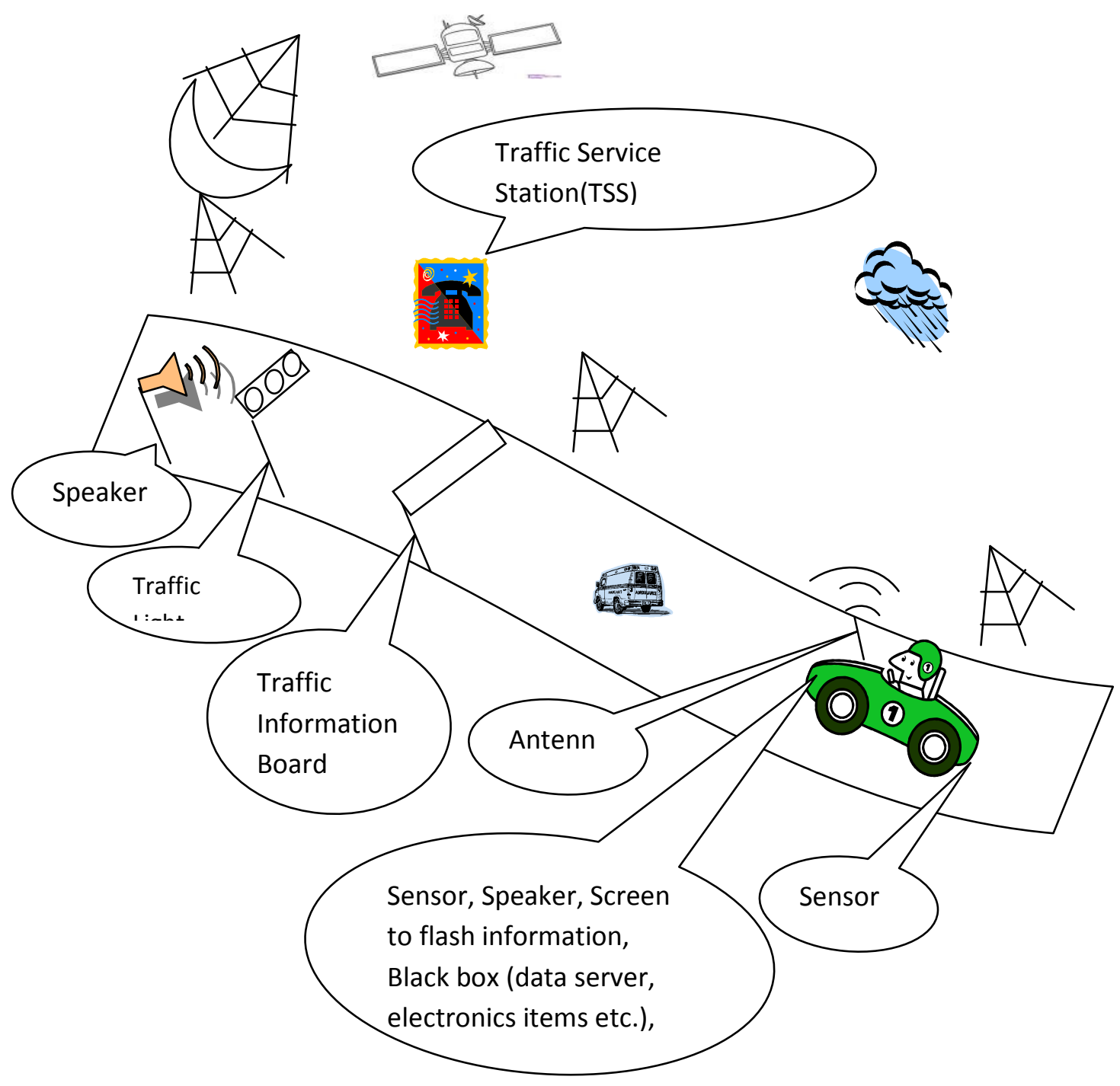

Fig. 3: Proposed view of highway system 
International Journal of Distributed and Parallel Systems (IJDPS) Vol.3, No.5, September 2012

\section{THE PERFORMANCE ANALYSIS OF THE PROPOSED MODEL AND EXPERIMENTAL RESULT}

We have used the following routing algorithm for experiments:

//Routing algorithm

STEP 1: START

STEP 2: If found problem then wait and goto start

STEP 3: Else move

//traffic service station(TSS) will detect you and send available routing information

STEP 4: Accept routing information

STEP 5: Find the shortest path and move in selected route OR move in the available route

STEP 6: If TSS is sending any message about Jam/Accident or any such type of problem with alternate routing information then read traffic information board STEP 7: If problem is found, then choose among available route and proceed else ignore the message

STEP 8: else move on

STEP 9: STOP

We consider an example of highway, we denote crossings with $\mathrm{Ni}$, where $\mathrm{i}=1,2,3,4,5,6,7,8,9,10$ and road with $\mathrm{Ri}$, where $\mathrm{i}=1,2,3,4,5,6,7,8,9,10,11,12$.

Suppose, we start from R2 and we have to go to R8. Then following routing information will be available:

i. R2->R1->R3->R5->R7->R8

ii.R2->R1->R16->R17->R18->R15->R7->R8

iii.R2->R1->R16->R17->R13->R5->R7->R8

iv.R2->R1->R3->R13->R18->R15->R7->R8

We can choose any route and proceed with the help to above algorithm on the proposed infrastructure. Of course waiting will be here if N7 or N8 fails. Solution is obvious.

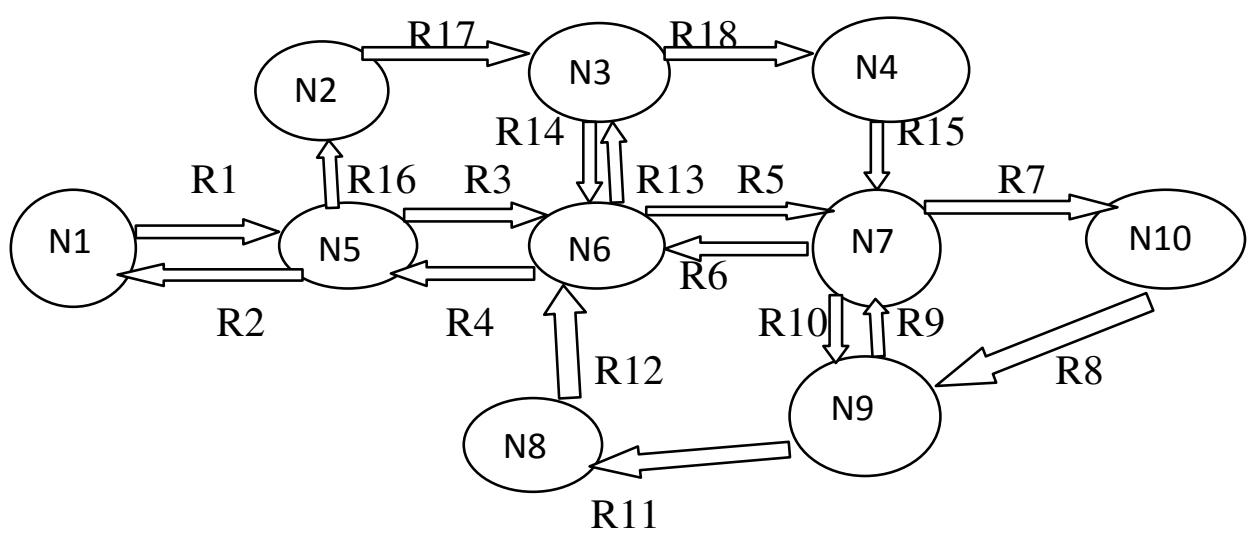

Fig. 4: An example of highway 
International Journal of Distributed and Parallel Systems (IJDPS) Vol.3, No.5, September 2012

This is just an instant of highway. It runs for any instant. After the successful running of programs and success of experiments, we can say that above will create a magic on the road.

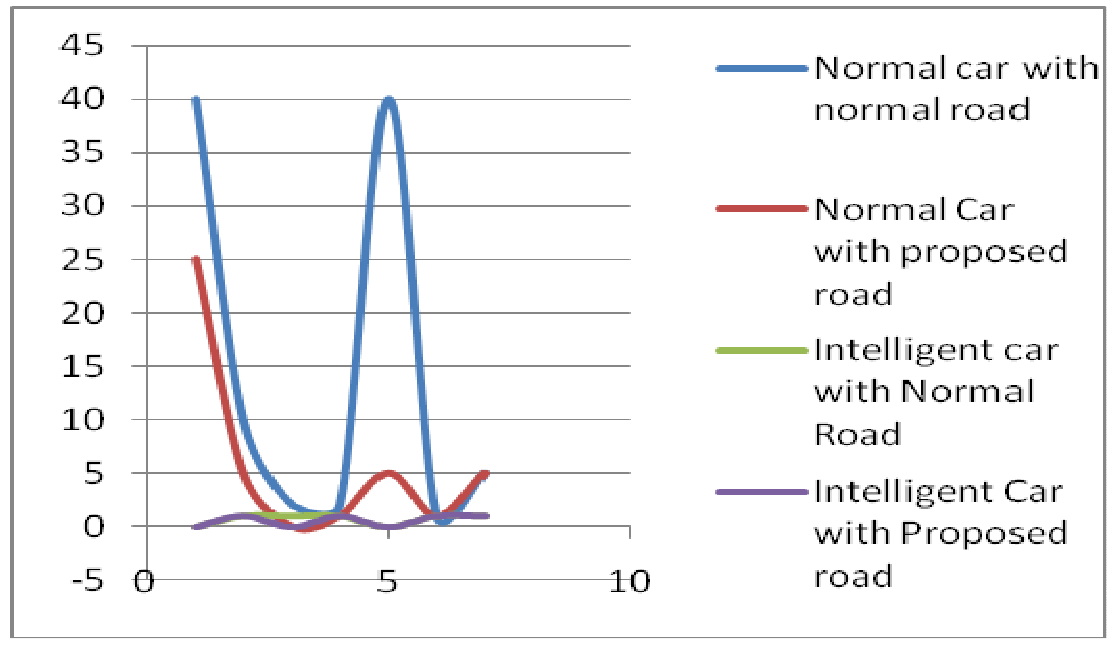

We also found that above model will not work properly in the following conditions:

1. If we ignore the TSS message in dangerous zone or in serious condition.

2. Complete shutdown of TSS.

We are not considering other's instantaneous fault as a problem because we suppose that every vehicle is an intelligent electronic vehicle.

This car will keep an up to second record of our driving from the instant we start it up, and be able to transmit data in addition to saving it to data server-including where we went, the route we look and how fast we drove-over wireless network.

\section{CONCLUSION AND FUTURE PROSPECTS}

The proposed level of incorporating systems into electronic car shows that this intelligent car will be a fully autonomous with driver warning system. In the future, real time experiments of the proposed car with proposed infrastructure with wireless technologies will happen. Then we can go for its commercial use.

\section{REFERENCES}

1. Ambudkar B.,"'Sensored car", IEEE $2^{\text {nd }}$ international conference on computer and electrical engg, IEEE computer Society, pp.335-338,2009.

2. Bian M, Li K, Jin D, Lian X “ A velocity control strategy for vehicular collision avoidance system" Proceedings of the IEEE international conference on mechatronics and automation, Niagars Falls, Canada, pp. 1827-1830, July, 2005.

3. B. Heisele, P. Ho, T. Poggio, "Face Recognition with Support Vector Machines: Global versus Component-based Approach", Proc. of the $8^{\text {th }}$ IEEE International Conference on Computer Vision, ICCV, Vol. 2, pp.688-694,2001. 
International Journal of Distributed and Parallel Systems (IJDPS) Vol.3, No.5, September 2012

4. Boyraz P, John H,"Active accident avoidance case study: Integrating drowsiness monitoring system with lateral control and speed regulation in passenger vehicles", Proceedings of IEEE international conference on vehicular electronics and safety, Columbus, USA, pp.293-298,2008.

5. Brännström, M. ; Sjöberg, J. ; Coelingh, E. "A situation and threat assessment algorithm for a rear-end collision avoidance system”, Intelligent Vehicles Symposium, IEEE,pp.102-107,2008.

6. Dasgupta C,"Application of GPS and infrared for car navigation in foggy condition to avoid accident", IEEE $2^{\text {nd }}$ international conference on computer Engg and applications, IEEE computer Society, pp.238-241, 2010.

7. Eidehall A, Pohl J, Gustafsson F and Ekmark J.,’'Towards autonomous collision avoidance by steering", IEEE transaction on Intelligent transportation system, Vol.8, No.1,pp.84-94,2007.

8. Ertlmeier R., Spannaus P.," Expanding design process of the airbag control unit ACU-connection of active and passive safety by using vehicle dynamics for rollover and side crash detection", International workshop on intelligent solution in embedded systems, pp.1-9,2008.

9. Ferrara A. and Vecchio C., "Cruise control with collision avoidance for cars via sliding models" Proceedings of the IEEE international conference on control applications, Munich, Germany, pp.2808-2813, 2006.

10. Ferrara A., "Automatic pre-crash collision avoidance in cars", Proceedings of IEEE intelligent vehicles symposlium, University of Perma, Italy, pp.133-138, June,2004.

11. Hillenbrand Jorg, Kroschel K., " A study on the performance of uncooperative collision migration systems at intersection like traffic situations" IEEE conference on cybernetics and intelligent systems, pp. 1-6, June 2006.

12. Jones W. D., "Black boxes get green light", IEEE Spectrum, pp.14-15, December,2004.

13. Nagaraj N.S. "Elements of electronic navigation system", TMH publication, 2008.

14. Nedevschi Sergiu, Vatavu A., Oniga F. and Meinecke M.M, "Forward collision detection using a stereo vision system", Proceedings of IEEE $4^{\text {th }}$ international conference on intelligent computer and processing, pp.115-122,2008.

15. Yang L and Wang F. Y., "Driving into intelligent spaces with pervasive communications" IEEE transaction on intelligent transportation systems, published by IEEE computer Society, pp.12-15, Jan-Feb, 2007.

16. Yang Sibo, Gechter Frank and Koukam A., "Application of reactive multi agent system to vehicle collision avoidance", $20^{\text {th }}$ IEEE international conference on tools with artificial intelligence, IEEE computer Society, pp.197-204, 2008.

17. Zhihong Z, Yongjia Z and Zonggi G.,"Design of intelligent car based on sound source guidance", The $2^{\text {nd }}$ international conference on computer and automation engineering, pp.26-29, 2010.

18. Zhenlin LU,Jingjiau LI and Minghui Z.,'Intelligent control research based on the smart car",IEEE $2^{\text {nd }}$ international conference on advanced computer control,pp.292-297,2010.

19. Zocchi C, Rovetta E A, Fanfulla F," Physiological parameters variation during driving simulations" IEEE international conference on Advanced intelligent mechatronics, , pp.1-6, 2007.

20. Zhang Z., Li S. and Zhang Jie., "Research of intelligent vehicle active safety system" Proceedings of the $2^{\text {nd }}$ international conference on information technology and computer science, IEEE computer Society, pp.301-304, 2010. 